\title{
A Proof-of-Concept Assessment of the Safety and Efficacy of Intralesional Diclofenac in the Treatment of Cutaneous Neurofibromas
}

\author{
Mauro Geller1,2.3* Aguinaldo Bonalumi Filho,,5, Lisa Oliveira1, Allan E. Rubenstein', \\ Luiz Guilherme Darrigo Jr.7, David Azulay ${ }^{8}$, Allan Bernacchi', \\ Marcia Gonçalves Ribeiro $^{3}$, Karin Soares Gonçalves Cunha ${ }^{10}$ \\ ${ }^{1}$ Immunology Department, Fundação Educacional Serra dos Órgãos (UNIFESO), Teresópolis, Brazil \\ ${ }^{2}$ Clinical Immunology, Instituto de Pós-Graduação Médica Carlos Chagas (IPGMCC,) Rio de Janeiro, Brazil \\ ${ }^{3}$ Medical Genetics Service, IPPMG-Universidade Federal Rio de Janeiro, Rio de Janeiro, Brazil \\ ${ }^{4}$ Hospital Naval Marcílio Dias, Rio de Janeiro, Brazil \\ ${ }^{5}$ Sociedade Evangélica Beneficiente de Curitiba Outpatient Unit, Curitiba, Brazil \\ ${ }^{6} \mathrm{NYU}$ Langone Medical Center, New York, NY, USA \\ ${ }^{7}$ Bone Marrow Transplant Unit, Hospital das Clínicas da Faculdade de Medicina de Ribeirão Preto, Universidade \\ de São Paulo (USP), Ribeirão Preto, Brazil \\ ${ }^{8}$ Pontifica Universidade Católica do Rio de Janeiro (PUC-RJ), Rio de Janeiro, RJ, Brazil \\ ${ }^{9}$ Plastic Surgery Post-Graduation, PUC-RJ, Rio de Janeiro, Brazil \\ ${ }^{10}$ Universidade Federal Fluminense (UFF), Rio de Janeiro, Brazil \\ Email: *maurogeller@gmail.com
}

Received 5 November 2015; accepted 28 December 2015; published 31 December 2015

Copyright (C) 2015 by authors and Scientific Research Publishing Inc.

This work is licensed under the Creative Commons Attribution International License (CC BY).

http://creativecommons.org/licenses/by/4.0/

(c) $\underset{\mathrm{EY}}{\mathrm{E}}$ Open Access

\section{Abstract}

The objectives of this study were to assess the safety and efficacy of intralesionally administered diclofenac in the treatment of cutaneous neurofibromas in patients with NF1. This was a proof-ofconcept, prospective, safety and efficacy study of the effect of intralesionally administered diclofenac $25 \mathrm{mg} / \mathrm{ml}$ given once a week to 3 target cutaneous neurofibromas for 4 consecutive weeks. Overall, there was no significant change in neurofibroma size. During the study, some treated lesions developed signs of necrosis and fell off after a few weeks, but none of the control neurofibromas fell off. There were no significant changes in patient's vital signs. A few adverse events occurred, mostly at the injection sites. During the study, some neurofibromas developed necrosis after the diclofenac injections and eventually detached from the patient. Overall, diclofenac was well tolerated, suggesting minimal systemic exposure, which required confirmation and further

\footnotetext{
"Corresponding author.
}

How to cite this paper: Geller, M., et al. (2015) A Proof-of-Concept Assessment of the Safety and Efficacy of Intralesional Diclofenac in the Treatment of Cutaneous Neurofibromas. International Journal of Clinical Medicine, 6, 975-983.

http://dx.doi.org/10.4236/ijcm.2015.612128 
studies, including bioavailability analysis.

Keywords

Neurofibromatosis Type 1, Cutaneous Neurofibromas, Diclofenac Sodium

\section{Introduction}

Neurofibromatosis type 1 (NF1) is an autosomal dominant neurocutaneous syndrome with highly variable clinical manifestations which have an incidence of approximately 1/4000 worldwide. NF1 is extremely variable, with numerous manifestations that may be presented at birth or may develop at any age [1]. The most common lesion in NF1 is the cutaneous neurofibroma, which appears on the skin in $90 \%$ of adults with NF1. Cutaneous neurofibromas are benign tumors, presumably of peripheral nerve sheath origin. Their number in an affected individual can range from a few to thousands. Cutaneous neurofibromas are uniformly benign and first appear on the torso around adolescence, but can appear anywhere in the dermis or subcutis [2].

Cosmetic problems from cutaneous neurofibromas are a common complaint of NF1 patients [1]. Neurofibromas may also cause itching and are occasionally painful [1]. The lesions can be removed surgically, but other lesions may develop and surgical removal is painful and leaves scars. Currently, there is no known treatment other than surgical removal by scalpel, electro-dessication or laser [1] [3].

The superficial location of cutaneous neurofibromas makes them amenable to intralesional therapy. The ideal intralesional treatment will involve a compound that induces cutaneous neurofibromas to involute without scarring and/or that prevents them from growing larger in size. Diclofenac is a nonsteroidal anti-inflammatory drug (NSAID) that also exhibits analgesic and antipyretic activity. Diclofenac and other NSAIDs inhibit the biosynthesis of prostaglandins by preventing the substrate arachidonic acid from binding to the cyclooxygenase (COX) enzyme active site [3]. The COX enzyme has two isoforms, COX-1 and COX-2. COX-1 is expressed in the most cells and catalyzes the production of prostaglandins involved in numerous physiological functions, including maintenance of renal function, mucosal protection in the gastrointestinal tract and pro-aggregatory thromboxane $A_{2}$ in the platelets [4]-[6]. COX-2 is considered to be induced by cytokines and inflammatory mediators in various tissues, including endothelial cells.

When administered topically, diclofenac causes the clearance of actinic keratosis lesions. Topical diclofenac $3 \%$ utilizes a gel vehicle to deliver the drug to the epidermis. The mechanism of action of topical diclofenac 3\% gel is not known, but the topical formulation drug has been shown to cause inhibit angiogenesis and induce neovascular regression in inflammatory tissue in animal models [7] [8]. Because cutaneous neurofibromas are benign lesions that rely on cellular proliferation, diclofenac potentially may inhibit their growth much like it effectively retards and induces involution of actinic keratoses. Such a local effect can result in an effective therapy that involves little cosmetic disfigurement and maximal safety.

Diclofenac also exists as a $25 \mathrm{mg} / \mathrm{ml}$ injectable preparation (Voltaren ${ }^{\circledR}$ injection $75 \mathrm{mg} / 3 \mathrm{ml}$ ampoule). This formulation is approved in some countries for the treatment of pain as a result of renal colic, biliary colic, and migraine headaches [9]. Intralesional administration of diclofenac is not well-studied, with no recent reports in the literature that describe the use of this route of administration for the local treatment of any benign or malignant tumor. Though cutaneous neurofibromas are easily accessible lesions, presently available topical gel formulations of diclofenac are unlikely to penetrate the epidermis adequately to reach effective intralesional concentrations. Intralesional diclofenac may overcome this issue. For this reason, a novel use of injectable diclofenac $25 \mathrm{mg} / \mathrm{ml}$ was explored in this study. A clear benefit of locally introduced diclofenac when compared to oral diclofenac was the targeted delivery of a significantly lower dose of drug to patients.

In this study, over the course of 4 weeks, three different sized cutaneous neurofibromas were treated with different volumes of diclofenac $25 \mathrm{mg} / \mathrm{ml}$. This served to assess a differential response to diclofenac depending on the size of the lesion. Control lesions of comparable differing sizes were also "mock"-treated with sterile normal saline. Prior to injection with diclofenac the target lesions were anesthetized with lidocaine $1 \%$ combined with epinephrine 1:100,000. All lesions were located on the upper back in order to minimize the negative conse- 
quences of any potential local adverse effect of the injected drug.

\section{Objectives}

The objectives of this study were to assess the safety and efficacy of intralesionally administered diclofenac in the treatment of cutaneous neurofibromas in patients with NF1.

\section{Material and Methods}

\subsection{Subjects}

Seven (7) adults with an established diagnosis of NF1 provided informed consent. All subjects were female, ages between 18 and 65, inclusive, who were neither pregnant nor breastfeeding, who were otherwise healthy and possessing at least 6 cutaneous neurofibromas between 0.5 and $1.5 \mathrm{~cm}$ (measured in the largest dimension), inclusive, on the upper back. NF1 was defined as a genetic mutation involving the gene encoding neurofibromin confirmed by mutation analysis, or by fulfilling classical clinical criteria: the presence of any 2 of the following 7 features: $\geq 6$ café au lait macules on the body of greater than $15 \mathrm{~mm}$ in diameter in the longest dimension; two or more cutaneous neurofibromas or one plexiform neurofibroma; freckling in axillary or inguinal regions; an optic glioma; two or more Lisch nodules (iris hamartomas), a distinctive osseous lesion of neurofibromatosis, such as sphenoid wing dysplasia, pseudoarthrosis of the tibia, macrocephaly, or scoliosis; and a first degree relative with NF1.

All subjects were in good health or had stable concomitant medical conditions appropriately managed by a primary care physician. Enrolled subjects demonstrated no clinically significant abnormalities on both laboratory and physical examination, other than for clinical signs of NF1.

\subsection{Material \& Methods}

Diclofenac 25 mg/ml (brand name Voltaren ${ }^{\circledR}$, obtained from Drogarias Pacheco Av. Ataulfo de Paiva, 386 Leblon-Rio de Janeiro/RJ, Brazil) was injected intralesionally once a week to 3 target cutaneous neurofibromas for 4 consecutive weeks. After screening and enrollment, all subjects received a defined volume (based on the size of the lesion) of intralesional diclofenac $25 \mathrm{mg} / \mathrm{ml}$ once weekly into 3 target cutaneous neurofibromas that were 0.5 to $1.5 \mathrm{~cm}$ in diameter, inclusive, in its largest dimension.

Each target cutaneous neurofibroma was different in size, with one 0.5 to $0.8 \mathrm{~cm}$ in diameter (referred to as T1), a second between 0.81 to $1.2 \mathrm{~cm}$ in diameter (T2), and a third 1.21 to $1.5 \mathrm{~cm}$ in diameter (T3). Concomitantly, three control cutaneous neurofibromas found on the upper back of the same range in sizes received sterile normal saline (C1, C2, and C3, respectively). All lesions prior to injection were locally anesthetized with lidocaine $1 \%$ and epinephrine 1:100,000. The volume of diclofenac $25 \mathrm{mg} / \mathrm{mL}$ or control solution injected into each neurofibroma was as follows: T1/C1: $0.2 \mathrm{ml}$; T2/C2: $0.3 \mathrm{ml}$; T3/C3: $0.4 \mathrm{ml}$.

The study period lasted a total of 6 weeks, with a total of four patient visits: Screening/Baseline, Week 1, Week 2, Week 3, and Week 6. Patients were followed every week during receipt of the study medication and three weeks after the last dose had been administered. At every visit, subjects underwent serial physical examinations, recording of adverse events and concomitant medications, and measurement and photography of both the target and control lesions. Assessment included the exact measured dimensions (in two axes) of the two assessed lesions. Photography entailed standardized digital images of both the target and control lesions (accompanied by a measuring tape) without any identifying features of the subject represented. For each subject, photography involved consistent focal length, lighting, and angle of exposure carried over from visit to visit.

During each visit, each subject was questioned for potential side effects of the receipt of the study medication either during its administration or in between visits, including pain, pruritus, irritation, discoloration, ulceration, or any other new sign or symptom-either local or distant from the target and control lesions-not present at baseline.

\subsection{Evaluation of Efficacy and Tolerability}

Safety was evaluated by adverse event monitoring (including but not limited to systemic side effects and abnormal laboratory evaluations) and dermatological assessments of local (at the treated sites) and global skin 
reactions. Efficacy was evaluated with both physical measurement and photography of the target and control lesions at every visit after the baseline visit.

At the screening visit, informed consent was obtained, inclusionary and exclusionary criteria were reviewed, and a full medical history, physical examination, and a baseline laboratory evaluation were performed. Subjects with the diagnosis of NF1 who had given informed consent, who met all of the inclusionary and exclusionary criteria, who were in good general health or with concomitant medical conditions that were stable and managed by a primary care physician, and who had no significant laboratory abnormalities, initiated the treatment period at a baseline visit which was within one week of the screening visit. Throughout the 7-week duration of the study no other established approaches to the treatment of cutaneous neurofibromas was allowed. Both the target and control cutaneous neurofibromas had not received therapy of any nature-surgical or medical-for at least 3 months prior to study entry.

At the screening visit, a full medical history was obtained, a complete physical examination, including vital signs, was recorded, concomitant medications were noted, and laboratory evaluations were performed. The laboratory evaluations included a complete blood count, liver function tests, and a comprehensive metabolic examination (not including lipid profile). A urinalysis was performed. Women of childbearing potential received a urine pregnancy test. In subjects meeting the inclusion and exclusion criteria, target and control cutaneous neurofibromas of the correct size and on the upper back were identified and noted-using measurements from anatomical landmarks-in terms of exact location and size.

Adverse events were monitored at all site visits, starting immediately after the patient had signed informed consent to participate in the study. The subjects were queried for any adverse events that occurred between visits. Concomitant medication use was monitored and recorded at screening evaluation and was continued throughout the course of the study, up to and including the final follow-up visit. Safety was evaluated by adverse event monitoring (including but not limited to systemic side effects and abnormal laboratory evaluations) and dermatological assessments of local and global skin reactions. To elicit adverse events, simple questions with minimal connotations were used as the initial questions at all evaluation points during the study. For example:

- How have you felt since your last visit?

- Have you had any health problems since you were last here?

- Have you had any unusual or unexpected worsening of your medical condition?

Study data were recorded in the clinical research form and tabulated in Excel. Continuous variables were analyzed using one-way ANOVA with the software GraphPad Prism 5.

\section{Results}

A total of 7 female patients, aged 46 to 56 years, were enrolled in the study. They were neither pregnant nor breast feeding, were otherwise healthy and possessing at least 6 cutaneous neurofibromas between 0.5 and 1.5 $\mathrm{cm}$. Throughout the 7-week duration of the study, no other established approaches to the treatments of cutaneous neurofibromas was allowed.

At the screening visit, a full medical history was obtained, a complete physical examination, including vital signs, was recorded, concomitant medications were noted, and laboratory evaluations were performed. All subjects were reevaluated during the 7-week duration of the study and, as shown below (Table 1), there were no significant changes in patients' vital signs throughout the study.

During the treatment period, adverse events were monitored at all the injection sites at every visit. All 7 patients presented with abnormal clinical labs during the study, one patient presented a cold and evidence of necrosis in T3, one patient presented some flaccidity in C3, one patient presented asthma, necrosis on neurofibroma on left hip and redness and exulceration in T2 (Table 2).

All 6 cutaneous neurofibromas possessed between 0.5 and $1.5 \mathrm{~cm}$ in diameter, inclusive, in its largest dimension. Three target cutaneous neurofibromas were chosen for the treatment with the diclofenac injection and on the other three cutaneous neurofibromas were given the sterile normal saline injection. The results of these injections are presented below (Table 3 and Table 4).

Although with few exceptions there was no significant change in neurofibroma size, during the study some patients presented with signs of necrosis in the injection sites of the treated neurofibromas. After a few weeks, the neurofibromas that showed some necrosis eventually detached from the patient. The process can be visualized in Figures 1-4. This process was not observed among the control neurofibromas. 
Table 1. Vital signs monitored during the treatment period.

\begin{tabular}{ccccccc}
\hline & Baseline & Week 1 & Week 2 & Week 3 & Week 6 & $\begin{array}{c}\text { Change from } \\
\text { Baseline? }\end{array}$ \\
\hline Temperature $\left({ }^{\circ} \mathrm{C}\right)$ & $36.67( \pm 0.125)$ & $36.61( \pm 0.491)$ & $36.17( \pm 0.439)$ & $36.46( \pm 0.632)$ & $36.29( \pm 0.481)$ & No $(\mathrm{p}=0.166)$ \\
Pulse rate $(\mathrm{bpm})$ & $63.14( \pm 10.93)$ & $81.57( \pm 33.51)$ & $67.0( \pm 9.147)$ & $66.57( \pm 9.217)$ & $79.71( \pm 9.69)$ & No $(\mathrm{p}=0.218)$ \\
Respiratory rate (ipm) & $22.57( \pm 6.347)$ & $21.43( \pm 5.711)$ & $19.86( \pm 1.574)$ & $20.71( \pm 4.152)$ & $20.86( \pm 4.88)$ & No $(\mathrm{p}=0.789)$ \\
Systolic blood pressure $(\mathrm{mmHg})$ & $127.1( \pm 30.39)$ & $127.1( \pm 24.98)$ & $124.3( \pm 18.13)$ & $121.4( \pm 19.52)$ & $120.0( \pm 20.0)$ & No $(\mathrm{p}=0.438)$ \\
Diastolic blood pressure $(\mathrm{mmHg})$ & $80.14( \pm 14.03)$ & $85.0( \pm 9.574)$ & $85.71( \pm 5.345)$ & $84.29( \pm 7.868)$ & $77.14( \pm 7.559)$ & Yes $(\mathrm{p}=0.041)$ \\
\hline
\end{tabular}

Data are means $( \pm \mathrm{SD})$ and results of one-way ANOVA.

Table 2. Adverse events recorded during the treatment period.

\begin{tabular}{|c|c|c|c|c|c|c|c|}
\hline & \multicolumn{7}{|c|}{ Patient } \\
\hline & 1101 & 1102 & 1103 & 1104 & 1105 & 1106 & 1107 \\
\hline Asthma & & & & $\mathrm{x}$ & & & \\
\hline Cold (flu) & & $\mathrm{x}$ & & & & & \\
\hline Elevated ALT & $\mathrm{x}$ & & & & & & \\
\hline Elevated direct billirubin & $\mathrm{x}$ & & & & & & \\
\hline Elevated eosinophils & $\mathrm{x}$ & & & $\mathrm{x}$ & $\mathrm{x}$ & & \\
\hline Elevated monocytes & $\mathrm{x}$ & & & $\mathrm{x}$ & & & \\
\hline Elevated neutrophils & & & & & & $\mathrm{x}$ & $\mathrm{x}$ \\
\hline Elevated serum alkaline phosphatase & $\mathrm{x}$ & & & & & & \\
\hline Elevated urinalysis-blood & & & & & & $\mathrm{x}$ & \\
\hline Elevated white blood cell count & & & & & & $\mathrm{x}$ & \\
\hline Headache & & $\mathrm{x}$ & & & $\mathrm{x}$ & $\mathrm{x}$ & \\
\hline Reduced hematocrit & $\mathrm{x}$ & & & & & $\mathrm{x}$ & \\
\hline Reduced hemoglobin & $\mathrm{x}$ & & & & & $\mathrm{x}$ & \\
\hline Reduced magnesium & & & & $\mathrm{x}$ & & & \\
\hline Reduced total globulin & $\mathrm{x}$ & $\mathrm{x}$ & $\mathrm{x}$ & $\mathrm{x}$ & $\mathrm{x}$ & $\mathrm{x}$ & $\mathrm{x}$ \\
\hline
\end{tabular}

$\mathrm{x}=$ Positive Adverse Event; $\mathrm{T}$ = Neurofibroma treated with diclofenac; $\mathrm{C}$ = Control neurofibroma.

Table 3. Change in neurofibroma size during the treatment period.

\begin{tabular}{cccccccccc}
\hline \multicolumn{7}{c}{ Change in Neurofibroma Size ( $\boldsymbol{p}$ values) } & & & \\
\hline & 1101 & 1102 & 1103 & 1104 & 1105 & 1106 & 1107 \\
\hline T1 & 0.5000 & 0.0789 & 0.2435 & NS & 0.5000 & 0.5468 & 1 \\
T2 & 0.5000 & 0.9259 & 0.7530 & 0.0210 & 0.0100 & 0.7183 & 0.1903 \\
T3 & 0.0486 & 0.2915 & 0.0012 & 0.0628 & 0.2817 & 0.0389 & 0.4205 \\
C1 & 0.6238 & 0.0233 & 1.000 & 0.5000 & 0.1040 & 0.0022 & 0.1040 \\
C2 & 0.1263 & 0.0320 & 0.8270 & 0.6480 & 0.9830 & 0.9446 & 0.0384 \\
C3 & 0.0233 & 0.2258 & 0.1611 & 0.7030 & 0.2682 & 0.3061 & 0.0486 \\
\hline
\end{tabular}

Data are results of one-way ANOVA; $\mathrm{T}$ = Target neurofibroma; $\mathrm{C}$ = Control neurofibroma. 
Table 4. Changes in neurofibromas observed during the treatment period.

\begin{tabular}{|c|c|c|c|c|c|c|c|}
\hline & \multicolumn{7}{|c|}{ Patient } \\
\hline & 1101 & 1102 & 1103 & 1104 & 1105 & 1106 & 1107 \\
\hline Edema & & & & & & $\mathrm{T} 3$ & \\
\hline Exulceration & & Т3 & & T2, T3 & $\mathrm{T} 2$ & T3 & T3 \\
\hline Hyperpigmentation & $\mathrm{T} 1$ & & T3 & & & & T3 \\
\hline Necrosis & $\mathrm{T} 2, \mathrm{~T} 3$ & T3 & $\mathrm{T} 1, \mathrm{~T} 2$ & $\mathrm{~T} 3$ & & $\mathrm{~T} 1, \mathrm{~T} 2, \mathrm{~T} 3$ & $\mathrm{~T} 1, \mathrm{~T} 2, \mathrm{~T} 3$ \\
\hline Pain & & & & & & $\mathrm{T} 3$ & \\
\hline $\begin{array}{c}\text { Part or all of } \\
\text { neurofibroma fell off }\end{array}$ & $\mathrm{T} 2, \mathrm{~T} 3$ & & $\mathrm{~T} 1, \mathrm{~T} 2$ & $\mathrm{~T} 1$ & & & $\mathrm{~T} 1, \mathrm{~T} 2, \mathrm{~T} 3$ \\
\hline $\begin{array}{c}\text { Post-injection } \\
\text { burning sensation }\end{array}$ & $\mathrm{T} 1, \mathrm{~T} 3$ & T1, T2, T3 & $\mathrm{T} 1$ & $\mathrm{~T} 1, \mathrm{~T} 2$ & & $\mathrm{~T} 1, \mathrm{~T} 2, \mathrm{~T} 3$ & \\
\hline Pruritis & $\mathrm{T} 1, \mathrm{~T} 2, \mathrm{~T} 3$ & T1, T2, T3 & $\mathrm{T} 1, \mathrm{~T} 2, \mathrm{~T} 3$ & $\mathrm{~T} 1, \mathrm{~T} 2, \mathrm{~T} 3$ & $\mathrm{~T} 1, \mathrm{~T} 2, \mathrm{~T} 3$ & $\mathrm{~T} 1, \mathrm{~T} 2, \mathrm{~T} 3$ & $\mathrm{~T} 1, \mathrm{~T} 2, \mathrm{~T} 3$ \\
\hline Prurulent secretion & & & & $\mathrm{T} 3$ & & & \\
\hline Redness & T3 & & & $\mathrm{T} 2, \mathrm{~T} 3$ & & $\mathrm{~T} 3$ & $\mathrm{~T} 1$ \\
\hline Volume reduction (flaccidity) & & $\mathrm{T} 1$ & $\begin{array}{l}\text { T1, T2, T3, } \\
\text { C3 }\end{array}$ & $\mathrm{T} 1$ & & & \\
\hline
\end{tabular}

Changes and observations noted in neurofibromas of treated patients during the study. $\mathrm{T}=$ Target neurofibroma; $\mathrm{C}=\mathrm{Control}$ neurofibroma.

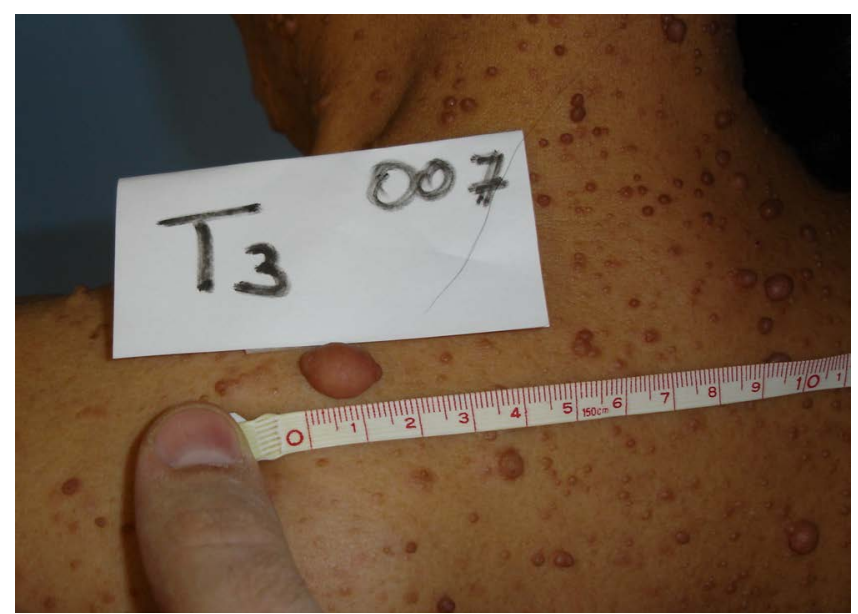

Figure 1. Neurofibroma before starting the treatment.

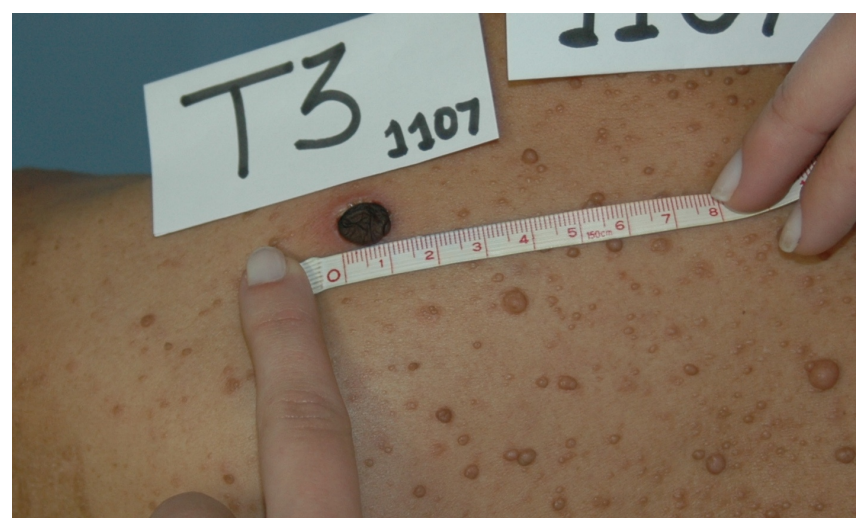

Figure 2. Neurofibroma during week 3 of treatment. 


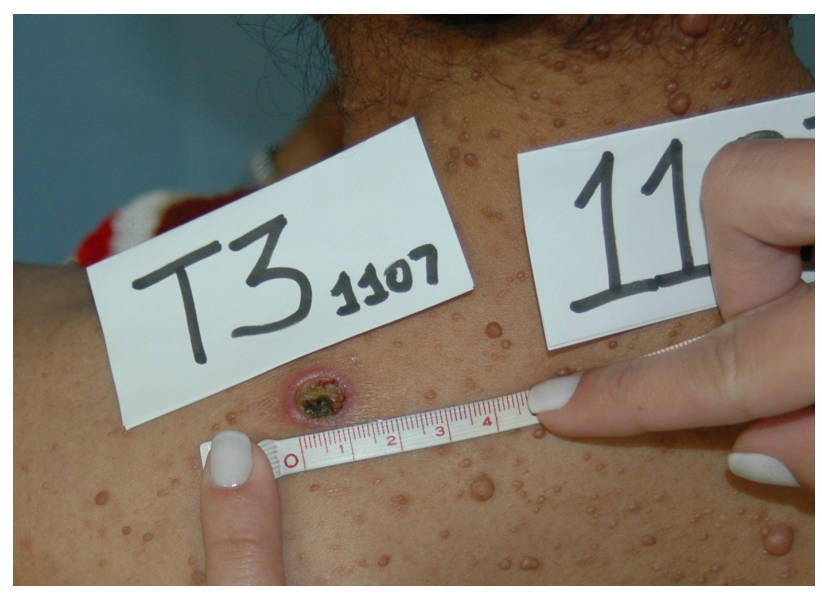

Figure 3. Neurofibroma during week 6 of treatment.

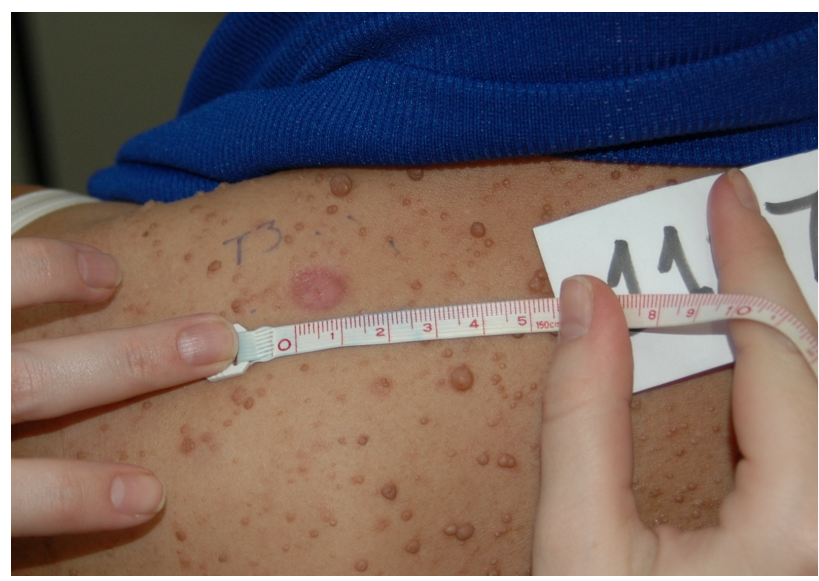

Figure 4. Neurofibroma after three months of the end of the treatment.

\section{Discussion}

Cutaneous neurofibromas can occur anywhere on the body, presenting a wide variation in their size, numbers and shape [10]-[12]. They occur in more than 95\% of patients and are composed of all cell types found in the peripheral nerves [13]-[15]. Generally, they are dome-shaped, soft, fleshy and skin color tumors [10]. Cutaneous neurofibromas can cause extreme cosmetic disfigurement or discomfort [15]. Removal by an expert surgeon is the only type of treatment available so far, though aside from the electrodessication technique, most procedures leave scars and carry the risk of keloid formation [3].

Nonsteroidal anti-inflamatory drugs including diclofenac are most commonly used in inflammatory diseases, since they are effective in management of pain, fever, redness and edema arising as a consequence of inflammatory mediator release [16] [17]. In mice, they are capable of stimulating proliferation of hematopoietic stem cells, to enhance bone marrow and splenic hematopoiesis, and bone marrow erythropoiesis [18].

During our literary search, we did not find any source that contained diclofenac's bioavailability after subcutaneous injection.

During the course of treatment, there were no significant changes in vital signs and few adverse effects. Although there was not an important alteration in size of the neurofibromas during the duration of the study, some patients presented with necrosis in the diclofenac injection sites and later the neurofibroma detached from the patient. This is a possible new type of treatment for cutaneous neurofibromas, but since our $n$ was not vast-indeed, limited sample size and inclusion of only female subjects were two important limitations of this study, we advise that further studies should be done on the subject. Based on the results of this study, we suggest that future investigations include observations of changes in neurofibroma characteristics rather than focusing solely 
on size when evaluating treatment efficacy.

All patients had reduced total globulin at the final study follow-up visit, however, we do not believe that this finding was associated with the diclofenac treatment, as the alterations were noted 3 weeks after the last diclofenac injections.

Interestingly, there were no reports of gastrointestinal side effects which are the most commonly reported effects associated with systemic diclofenac usage [13]. It may be that given the relatively small doses of diclofenac administered, systemic effects were kept to a minimum. Further studies testing serum diclofenac levels following this type of administration would be useful in confirming this observation.

Subsequent histopathology analysis of the treated neurofibromas that was not a part of the original protocol but that was carried out (following Ethical Committee approval of a protocol amendment) due to necrosis observed in the treated neurofibromas showed massive infiltration of inflammatory cells (neutrophils and lymphocytes) and thrombosis within or adjacent to the necrosis areas on the neurofibromas. Subtle changes in small blood vessels in relatively normal areas of the neurofibromas were also noted. No obvious increase in mast cell numbers was reported.

\section{Conclusion}

There were no significant changes in vital signs or patients well-being. The study did not show an important change in size reduction of the neurofibromas and in some cases, the neurofibroma grew despite the diclofenac injections. Nevertheless, some of the neurofibromas presented with necrosis and later on detached from the patient. Overall, diclofenac was well tolerated, suggesting minimal systemic exposure, which required confirmation and further studies, including bioavailability analysis. The observed necrosis and histopathology results warranted further investigation of diclofenac as a treatment option for cutaneous neurofibromas, though optimal dose and delivery system remained to be established.

\section{Ethical Standards}

The study protocol was submitted to and approved by the UNIFESO Ethical Committee and was performed in accordance with the ethical standards outlined in the 1964 Declaration of Helsinki and its later amendments, as well as local guidelines. All participants gave their informed consent prior to inclusion in the study.

\section{Acknowledgements}

The authors would like to thank Thaís Ogea Pereira, Kalynka Silvia Higino, Alessandra Santos, and Marcelo Paula Coutinho for help with patient screening, data collection, and help with the Case Report Forms; Ashley Nagle for help reviewing the paper, and Prof. Bruce Strober for protocol review. Thanks also to NexGenix for protocol review and support on scientific methodology, and to Elane Frossard, president of the Centro Nacional de Neurofibromatose (CNNF) for use of the facilities for screening and support with the patients. This study received support of a research grant from UNIFESO.

\section{Conflict of Interest}

The authors declare that they have no conflict of interest.

\section{References}

[1] Geller, M., Mezitis, S.G.E., Nunes, F.P., Ribeiro, M.G., Araújo, A.P.Q.C., Brosntein, M.D., Batista, R.S., Gomes, A.P., Oliveira, L. and Cunha, K.S.G. (2008) Progesterone and Estrogen Receptors in Neurofibromas of Patients with NF1. Journal of Clinical Pathology, 1, 93-97.

[2] Gutmann, D., Aylsworth, A., Carey, J.C., Korf, B., Marks, J., Pyeritz, R.E., Rubenstein, A. and Viskochil, D. (1997) The Diagnostic Evaluation and Multidisciplinary Management of Neurofibromatosis 1 and Neurofibromatosis 2. JAMA, 278, 51-57. http://dx.doi.org/10.1001/jama.1997.03550010065042

[3] Levine, S.M., Levine, E., Taub, P.J. and Weinberg, H. (2008) Electrosurgical Excision Technique for the Treatment of Multiple Cutaneous Lesions in Neurofibromatosis Type I. Journal of Plastic, Reconstructive \& Aesthetic Surgery, 61, 958-962. http://dx.doi.org/10.1016/j.bjps.2007.03.035

[4] Chen, Y.-F., Jobanputra, P., Barton, P., Bryan, S., Fry-Smith, A., Harris, G. and Taylor, R.S. (2008) Cyclooxygenase-2 
Selective Non-Steroidal Anti-Inflammatory Drugs (Etodolac, Meloxicam, Celecoxib, Rofecoxib, Etoricoxib, Valdecoxib and Lumiracoxib) for Osteoarthritis and Rheumatoid Arthritis: A Systematic Review and Economic Evaluation. Health Technology Assessment, 12, 1-278. http://dx.doi.org/10.3310/hta12110

[5] Conaghan, P.G. (2012) A Turbulent Decade for NSAIDs: Update on Current Concepts of Classification, Epidemiology, Comparative Efficacy, and Toxicity. Rheumatology International, 32, 1491-1502. http://dx.doi.org/10.1007/s00296-011-2263-6

[6] Pountos, I., Georgouli, T., Calori, G.M. and Giannoudis, P.V. (2012) Do Nonsteroidal Anti-Inflammatory Drugs Affect Bone Healing? A Critical Analysis. Scientific World Journal, 2012, Article ID: 606404. http://dx.doi.org/10.1100/2012/606404

[7] Medscape Drug Information: Topical Diclofenac. http://www.medscape.com/druginfo/dosage?cid=med\&drugid=22221\&drugname=Diclofenac+Sodium+Topical\&mon otype=default

[8] Ong, C.K., Lirk, P., Tan, C.H. and Seymour, R.A. (2007) An Evidence-Based Update on Nonsteroidal Anti-Inflammatory Drugs. Clinical Medicine \& Research, 5, 19-34. http://dx.doi.org/10.3121/cmr.2007.698

[9] Voltaren ${ }^{\circledR}$ Injection. http://www.medsafe.govt.nz/profs/datasheet/v/voltareninj.pdf

[10] Boyd, K.P., Korf, B.R. and Theos, A. (2009) Neurofibromatosis Type 1. Journal of the American Academy of Dermatology, 61, 1-16. http://dx.doi.org/10.1016/j.jaad.2008.12.051

[11] Ferner, R.E., Huson, S.M., Thomas, N., Moss, C., Willshaw, H., Evans, D.G., Upadhyaya, M., Towers, R., Gleeson, M., Steiger, C. and Kirby, A. (2007) Guidelines for the Diagnosis and Management of Individuals with Neurofibromatosis 1. Journal of Medical Genetics, 44, 81-88. http://dx.doi.org/10.1136/jmg.2006.045906

[12] Ferner, R.E. (2007) Neurofibromatosis 1. European Journal of Human Genetics, 15, 131-138. http://dx.doi.org/10.1038/sj.ejhg.5201676

[13] Gerber, P.A., Antal, A.S., Neumann, N.J., Homey, B., Matuschek, C., Peiper, M., Budach, W. and Bölke, E. (2009) Neurofibromatosis. European Journal of Medical Research, 14, 102-105.

[14] Hirsch, N.P., Murphy, A. and Radcliffe, J.J. (2001) Neurofibromatosis: Clinical Presentations and Anaesthetic Implications. British Journal of Anaesthesia, 86, 555-564. http://dx.doi.org/10.1093/bja/86.4.555

[15] Williams, V.C., Lucas, J., Babcock, M.A., Gutmann, D.H., Korf, B. and Maria, B.L. (2009) Neurofibromatosis Type 1 Revisited. Pediatrics, 123, 124-132. http://dx.doi.org/10.1542/peds.2007-3204

[16] Su, W.H., Cheng, M.H., Lee, W.L., Tsou, T.S., Chang, W.H., Chen, C.S. and Wang, P.H. (2010) Nonsteroidal Anti-Inflammatory Drugs for Wounds: Pain Relief or Excessive Scar Formation? Mediators of Inflammation, 2010, Article ID: 413238. http://dx.doi.org/10.1155/2010/413238

[17] Süleyman, H., Demircan, B. and Karagoz, Y. (2007) Anti-Inflammatory and Side Effects of Cyclooxygenase Inhibitors. Pharmacological Reports, 59, 247-258.

[18] Hofer, M., Pospisil, M., Hoferova, Z., Weiterova, L. and Komurkova, D. (2012) Stimulatory Action of Cyclooxygenase Inhibitors on Hematopoiesis: A Review. Molecules, 17, 5615-5625. http://dx.doi.org/10.3390/molecules17055615 